Portland State University

PDXScholar

$11-16-2018$

\title{
Breaking Binary Being in the Future Fiction of Star
} Trek

Jeremiah D. Ackerman

Portland State University

Follow this and additional works at: https://pdxscholar.library.pdx.edu/honorstheses

\section{Let us know how access to this document benefits you.}

\section{Recommended Citation}

Ackerman, Jeremiah D., "Breaking Binary Being in the Future Fiction of Star Trek" (2018). University Honors Theses. Paper 644.

https://doi.org/10.15760/honors.659

This Thesis is brought to you for free and open access. It has been accepted for inclusion in University Honors Theses by an authorized administrator of PDXScholar. Please contact us if we can make this document more accessible: pdxscholar@pdx.edu. 
Breaking Binary Being in the Future Fiction of Star Trek

\section{by}

\section{Jeremiah D. Ackerman}

An undergraduate honors thesis submitted in partial fulfillment of the

requirements for the deg
in
University Honors
and
Philosophy
Thesis Adviser
Brenda Glascott

Portland State University 
"It is good to have an end to journey toward; but it is the journey that matters, in the end."

- Ursula K. Le Guin, The Left Hand of Darkness

\section{( Set Phasers To Stun )}

When I was a kid, I read comic books like the "X-men" that dealt with how a group of people with mutant abilities sought to utilize their potential and exist peacefully alongside the rest of human society. In these stories, the mutant characters faced discrimination, prejudice, and termination often associated with the fears society had about their differences from the normal features of everyday people (non-mutants). I understood in my young mind that these mutants, although different, were also people. And over the years I continued to look at comic books/graphic novels, science fiction, and storytelling in general with a passion to understand what the stories that we create are saying about the human experience, people's differences, and the struggles people face within societies through history and into the future.

I was introduced to the franchise series Star Trek when I was eight years old, at the time when Star Trek: The Next Generation was in its second season. At the time I was not really aware of the philosophical content that was loaded into the episodes of the series, but I remember thinking, "This is the future; this is what the future looks like and this is what people do, and how they act, in the future." As a child, I perceived Star Trek as representing the results of human achievements and the progress that humanity will make in the future world, and beyond, a better place. It wasn't until much later that I came to understand that a core feature to the show's premise was the attempt to offer a more equitable human state of existence in a futurereality. I started to wonder if Star Trek was offering a fair projection of a truly more equitable society, if it offered representation of all kinds of people, or just certain types of people. I started watching Star Trek trying to discover what kinds of connections I could make between our real world in the present and the future world portrayed in Star Trek. What is Star Trek saying about 
social progress, changes in normative behaviors, empowerment of historically oppressed groups of people, and the inclusion of diverse or expanding nuances in things like gender and identity?

In this thesis, I refer to the "feminine" as having qualities or appearances traditionally associated with women (like delicacy, submissiveness/vulnerability, and prettiness), traits that have traditionally been cited as feminine but are not strictly universally identical. And I refer to the "masculine" as having qualities or appearances traditionally associated with men (like strength, aggressiveness, and stoicism). I use these general understandings to challenge the traditional and embedded views of those who see gender as a "binary" feature in which persons that are born with one of two sexed bodies (malelfemale) are associated with a gender that is naturally tied to being of male or female sex. Traditionally embedded ideas of the gender binary will be used to gauge whether characters and gender roles portrayed in Star Trek reflect ideas of hegemonic masculinity, or if they have envisioned broad and novel representations of beingness. There appears to be an underlying trend of binary ideas in the gender performances depicted in some stories about humanity's more equitable future, and not enough representations of alternative identity qualities.

The movements for trans-gender rights, gender equality and gender neutrality are emerging social justice issues in our current social and political discourses. Is science fiction is keeping up with the social movements that will affect societal changes of the future? Has Star Trek, specifically, been doing a good job in helping us to imagine alternate conditions, states, and possibilities? Does Star Trek offer an accurate account of the gender identity spectrum, or the possibility that gender roles could change over time? Can science fiction project an imaginative idea of the future that acts to potentially help us (the writer/reader/audience) 
envision progress that takes place in the future or do we utilize the imaginative future to work out problems we face in the present?

Michel Foucault's view of "episteme" in "The Order of Things" (chapters 4 - 5) frames the understanding of people's perspective and establishment of categorical knowledge as changing over time, in which societies and the things we take as regularities in knowledge are always changing. Foucault questions the authority of what is known by arguing that knowledge in this sense is limited by the way that people agree to use language, so what is known can only reflect the limits of a particular verbal system of the era. And so it is very likely that whatever the actual state of the future of things will or would be can only be spoken of unintelligibly in the present: how can we represent something in literature that we have yet to acknowledge, identify, or give a name to and incorporate into our language system? The challenge then is imagining completely unfamiliar features of the future within the discursive constraints of the present. With speculative fiction like Star Trek, I argue that the imagined future of beingness is often considerably constrained within a binary understanding of gender.

American literary critic Fredric Jameson, known for his analysis of contemporary cultural trends, believes that science-fiction storytelling does not only provide a way to imagine our future, but also to "de-familiarize and restructure our experience of our own present." (151) It is important for the audience of fantasy and science fiction, who actively looks at science fiction as a portal to the possibilities of our actual future, to keep in mind that Jameson is saying that science fiction is a way of using our imagination to alter our known reality. These texts give us the freedom to ask: - What if it was this way? What if features appeared different, or worked differently? What would that world be like? Would it be better, or worse? Imagination can help us envision our ideas of a better world, a more peaceful world, a more equitable future. But 
sometimes those visions are only partial; they can imagine a particular state of the world, but sometimes struggle to answer how society arrived at such a state.

There are different ways we can use our imagination to build concepts of how we see or understand the world. Storytelling found in narratives about life (ancestral knowledge of creation, folklore, dark fairy tales, historical master narratives, and religion) are examples of how imagination has been used to powerfully shape belief and action in the real world. Fiction about humanity's greater future might be said to have a degree of moral responsibility involved in what it depicts, since it offers its audiences a framework of the world that might allow for greater inclusiveness of diverse and emerging ideas, knowledge, and understanding, particularly through the representations of under-represented groups with alternative modes of identity that may be peripheral to mainstream culture.

In an interview that was hosted by Zoe Carpenter in Portland, Oregon, $13^{\text {th }}$, October, 2015, titled, "Listening to the Unheard Voices." the late American novelist, Ursula Le Guin, was asked to comment on her use of alternate political and social systems in the worlds she's created and the types of opportunities. that might not appear in realist fiction. Le Guin said,

"If you make it up you can open the doors to possibilities, whereas if you're writing metafiction, realistic fiction, fiction that says 'this is how it is' in a sense the doors are all closed."

Le Guin thinks that imaginative fiction allows us to go through these new doors and see what's on the other side and how things work there. Le Guin shared an anecdote from her life, in which a teenage fan of hers approached her and said "Do you know why I love Star Trek?" When Le Guin asked the young girl why, the teen replied, "Because it shows me a future where I can 
live." Le Guin thought this hope for a place where the teen belongs and is recognizable and fits in was what the young girl was getting from watching Star Trek and reading science fiction.

Carpenter concluded her interview asking Le Guin what she thought of "progress" as it might appear through storytelling, since Le Guin has thought so much about the future. Le Guin questioned what progress even means, but replied that she is only interested in the present and the past, because no one knows what the future is. She said, "The 'future' in science fiction is just a metaphor for 'now.'" (Le Guin). Le Guin thinks there has been progress in representing the broader scope of identity within a landscape of literature that had traditionally been mostly dominated by men's perspective and voices. But we often assume that "progress" means progress towards something better, nobler, more generous, more free; but you can progress towards evil just as easily. Le Guin is worried about becoming comfortable in thinking that if we have progress that we will be ok. She says that it's not just women's voices that are missing, women are just perhaps the largest part of the unheard voices that includes all kinds of other genders, and people of color, and that it is the unheard voices that need to be heard if we are going to start working towards a more equitable future -- in the present.

American philosopher and gender theorist, Judith Butler, author of Gender Trouble (1999) and Bodies That Matter: On The Discursive Limits of "Sex" (1993), thinks gender is something that is performative in that it produces a series of effects that consolidate an impression of being a man or a woman, but that no one is born a gender from the start. It is hard to account for gender accurately in the traditional binary because gender is culturally formed and a person has an agency of freedom over their own expression. What is most important is to resist the violence, discrimination and social stigmatization that are imposed by idealized gendered 
norms, especially against those who are gender different and gender non-conformant in their gender presentation.

Butler spoke at a lecture in Lisbon, Portugal on February 6, 2015 about gender recognition and discrimination, saying,

If we only stay with thoughts that are familiar to us, none of us would change; none of us would have the chance to regard the world we live in through another lens. The question of recognition is important, for if we say that we believe all humans deserve recognition - we presume that all human subjects are equally recognizable. But what if the field of appearance does not admit everyone? What is that? How is it that, that field is regulated in such a way that only certain kinds of beings can appear as recognizable subjects, and others not. Which humans count as human? (Butler, Why Bodies Matter")

Butler warns that we can become complacent in the ways in which we regard normative ideas about gender roles and neglect recognition of alternate gender identities in our daily lives. It is important to be aware of this and consider those who might be unrecognized, marginalized, or excluded when speaking of, depicting, and in effect representing an equitable world of representation. With Star Trek, I want to get a sense of how the gender roles and performances are displayed and consider if they tend to break traditional norms or reiterate mostly binary ideas of gender. Does Star Trek offer a genuine service of recognizing and representing individuals or groups that defy binary norms of gender? That which is included or excluded in stories about the future inform us about the present and possibly about how to perceive the future. By examining Star Trek, I look at widely syndicated stories in order to unearth a silent but observable narratives about binary norms. 


\section{Highly Illogical}

My literature review on how gender portrayed in Star Trek spans the scope of the original television series to the more recent television and film productions. I sought scholarly sources that examined whether a show often credited with the premise of portraying a more equitable future reproduces traditional gender roles or offers alternate gender identities. In this section, I will review what other scholars are saying about the performances of gender and sexuality in Star Trek media. Next, I will use an episode from Star Trek: The Next Generation, titled "The Outcast" (Season 5: Episode 17, air date: March, 16, 1992), to ask what might be happening within the context of this episode's portrayal of gender and what it offers in regards to representation of gender roles and sexuality. Finally, I will consider if Star Trek has successfully presented a progressive representation of gender performances.

Visual appearances, reactions, biases

Patricia Vettel-Becker's article, "Space and the Single Girl: Star Trek, Aesthetics, and 1960's Femininity", looks back on Star Trek's pilot series and other moments in the canon from the perspective of modern day feminism. Vettel-Becker seems to think there is plenty of scholarly review of how sexist the original Star Trek series is. She argues that the scholarship mostly attempts to work on addressing human liberties, but has misunderstood how visual aesthetics play just as important a role as the words in creating meaning in Star Trek. The original Star Trek series debuted with quite an effort of inclusivity; leading figures of the bridge included Asian, African and Russian crew members, as well as a female first officer, which Vettel-Becker describes is a part of Gene Roddenberry's original intended scope of the series, speaking to the culture of the time about a future that transcended racial and ideological 
prejudices, empowered women's civil liberation, and even foreshadowed the end of the Cold War.

In her article, Vettel refers to a necessity of space colonization (at least in the biological sense), which is that if man is going to colonize space he will need a woman who will bear children with him. And so a woman's presence in the stars seems logical. And although Vettel says many critics of Star Trek's original series focus on how women regulars in the series "played secondary roles to male leads" and how Starfleet women in miniskirts "functioned primarily as sexual playthings" to those leads, she does point out that in contrast to the domestic tasks of "celestial housekeeping" portrayed by the Robinsons mother in the TV series "Lost In Space", Starfleet women do not cook, clean, raise children or get married [mostly], but rather, are "professional women devoted to their careers who also delight in their femininity." (VettelBecker, 144 - 146) Vettel-Becker refers to Helen Gurley Brown's book, "Sex and the Single Girl" (1962), and points out that women of the 1960's were becoming very independent and they did not have to marry to have fulfilling lives, but instead were able to pursue satisfaction through career success, sexual liberation, and individual freedom to self-expression. Maintaining femininity in Star Trek was a triumph and a struggle, in that while expressing that gender equality would be achieved by the twenty-third century was a victory for liberal humanism, it also appeared to TV audiences of the time in an ultra-feminine way used to curb the fear of defeminization in cultural media. It strikes me that the show was praised for presenting a society that equally represented gender and gender roles but was received by its audiences with sexist fears about women.

In its breakout performances, Star Trek portrayed women who performed traditionally masculine traits, commanding, intelligent, and who carried an independence of expression and 
self-agency throughout the universe. Vettel-Becker explains that many aspects of rewriting the original characters were influenced in part by pushback against the strong "masculine nature" of some of the female characters. There was even resistance on the part of women to accept what they considered the masculinization of women, which had an effect on how the show's writing directed appearances. Vettel-Becker shares a quote from William Shatner that expresses how test screenings at the time (1965 -- 66) revealed that men and women both hated the pilot character "Number One" (who wasn't given any other name) and criticized the role because she seemed "'pushy" and "'annoying" by "'trying so hard to fit in with the men"” (qtd. by Vettel-Becker, 148). Following those test screenings in the shows production, scenes that showed strong female characters were eased back into a softer tone of expression. So there seems to be quite a mix of how people feel about gender and sexuality in the pilot series. As Vettel-Becker mentions, the discourse on that unfortunately has not been exhausted. During the course of this project, a trailer for CBS's 2019 winter season of Star Trek: Discovery shows the character Number One making a return into the current production, and I am curious to see how that portrayal is handled and how the critics and audiences respond.

It is important to keep in mind features of women's liberation and independence that are being expressed through Vettel-Becker's survey. She references a quote from Nichelle Nichols, who played Uhura in the original series cast. It is important to keep in mind this good statement about the time Star Trek emerged onto the scene. Nichols said,

'As the women's movement took hold in the seventies, people began to ask me about my costume. Some thought it "demeaning" for a woman in the command crew to be dressed so sexily. It always surprised me because I never saw it that way. After all, the show was created in the age of the miniskirt, and the crew 
women's uniforms were very comfortable. Contrary to what many people think today, no one really saw it as demeaning back then. In fact, the miniskirt was a symbol of sexual liberation. More to the point, though, in the twenty-third century, you are respected for your abilities regardless of what you do or do not wear.' (qtd. by Vettel-Becker 146)

Nichols defends the representation of her Starfleet apparel and the portal that took the liberation of the 60 's miniskirt to the respected freedom of uniform appearances in the twentythird century. Nichols points out that in this more equitable future, the idea of progress visually involves a focus on functionality and freedom, and not firm biases about flirtatious fashion flaws. In order to see the value of equality expressed through the visual portrayals of female characters with masculine traits that was attempted within the scope of Star Trek's vision, it should be considered first how these visuals are meant to be representative of a world that has dealt with the type social norms and commentary that contemporary debates still struggle with in the present.

Vettel-Becker argues that, "in Star Trek, beauty functions as a metaphor for humanity; and therefore it is beauty that humanizes outer space; that soothes anxiety over the terrifying unknown." (Vettel-Becker 172). I hope that beauty in this understanding lends to all genders, not only women, and is not reinscribing a binary system. But everything can be a metaphor of beauty and humanity, and beauty in the form of humanity can be potentially terrifying at times. For example, will humanity at large ever evolve beyond the use of warfare? In Star Trek, intergalactic warfare is a major component of Starfleet's reality, but how about something like gender discrimination? Does Star Trek try to offer ways to help us understand how they reached a more equitable society, concerning gendered issues and discrimination? 
Trying not to be Gendered

In, “This Species Which Is Not One: Identity Practices in Star Trek: Deep Space Nine," Kathy Ferguson also uses the philosophy of Foucault and Judith Butler to highlight the delimiting power of our intelligibility concerning the politics of sex and gender identities set within the larger political context of assumptions concerning the humanly livable life. Ferguson points out that in science fiction we have the special opportunity of calling the "human" into question in such a context where everyone is not aspiring to be "human." In this type of storytelling, we are able to see more in the field of appearances, including characters that defy the familiar categorization that readers and audiences bring with them. Ferguson believes that science fiction can bring "visibility" to what Butler identifies as "'certain habitual and violent presumptions" about what the "norms" in our range of perception about identity are and encourage us to think about different possibilities (qtd. by Ferguson 181). Ferguson agrees with other scholars about the portrayals and representation in corporate television science fiction, that it "stays in business and cultivates corporate sponsorship by conforming some of the cherished expectations held by readers/viewers" which she believes puts "centripetal and centrifugal" forces at play in the stories we see and read (181). Ferguson believes it is within this play of "resistance to and reauthorization of the normative practices of sex, gender, and humanity that science fiction plays out some of its feminist possibilities and limitations." (181) It seems like a struggle takes place behind the scenes of the production of Star Trek as it attempts to maintain a balance between what new limits it tests, regarding social normativity, and which ones it maintains for the purposes of pleasing the less progressive minded of its audiences.

Ferguson uses Foucault's two categories of heterotopias from Of Other Spaces (1986) to look at the space station of Star Trek: Deep Space Nine. They are the crisis heterotopias and the 
heterotopias of deviants, the former being privileged or sacred, reserved for those who are in a state of crisis in relation to their societal environment, and the latter housing those who are "deviant in relation to the required mean or norm" (182). Ferguson explains through Foucault's analogy of spaces that heterotopias connect with the "imagination and motion, suggesting they are spaces of both illusion and perfection" (182). Ferguson then goes on to talk about the Trill within ST:DS9, and wants to express her thought that “...all the interesting Trill characters developed in Star Trek have been female. That is, they are recognizable as women within the prevailing gender economy" (185). But that while the "sympathetic portrayal of love between two women challenges heterosexual normativity" (190), one character's behaviors "subordinates the symbiont to her own desires" (190), thereby, taming the potentially heterotopic practices and reestablishing hegemonic Trill norms of intelligibility.

The Trill is a humanoid species in the Star Trek universe that co-exist and share being with a symbiont. The synthesis of their two beings include the memories and abilities of previous hosts. The fierce competition for the few symbionts attracts the brightest and most highly motivated in Trill society. As such, Trills don't look for romance the way humans do. Joined Trills consider it quite a nuisance and view it as a weakness of the young. While hosts may have romantic feelings as often as any other sentient species, symbionts try to live on a higher, more spiritual plane and try to rise above those sorts of temptations. An interesting dualism exists in the Trills that kind of deals with the nature of the humanoid and the nature of a symbiont that finds human impulses fleeting and not necessary. The Dax symbiont has experienced both male and female gendered hosts multiple times throughout the Star Trek canon, and Ferguson uses Dax to inspect Trill positionality throughout her work. 
Ferguson believes that in Deep Space Nine the writers imagine a heterogeneous Trill identity but within a very homogenous Trill society. Ferguson is convinced that the material is over-influenced with "Hollywood bodies and truncated narratives" (194). Although allowing for more robust political analogies, the writers and producers of Star Trek center their unconventional approach to this society through the commercial expectations of their advertisers and the sexual anticipations of their largest audience, who are educated white men in their 30's. Ferguson says, "The popular circulation of images of a gender-bending doubled creature who is living a compelling and interesting life, one who is, simultaneously, attractively strange and strangely familiar, might contribute to the denaturalization of the prevailing and violent norms about bodies and identities" (194).

The Trill character, Dax, is able to embody and redirect what Judith Butler refers to as "'the ontological field in which bodies may be given legitimate expression"” (qtd. by Ferguson 194) through its complicated dualism of identity, which I think works to express separate needs and compromises in the union and shows that altogether the unity is more than beneficial. I believe that Ferguson draws on the powers of science fiction and the unique opportunity to speak of a being that takes host in male or female bodies to show how we can look at the intelligibility of being, and possession-ness of gender, in ways we do not conventionally conceive. It becomes apparent through her reading that she has been struggling with the traditional cues and tropes being reiterated throughout mainstream science fiction culture and Deep Space Nine in particular.

Post human thoughts about gender

Mia Consalvo offers an interesting interpretation of identity and gender through Star Trek's Borg Queen and the character Seven of Nine, from the Star Trek series Voyager. The 
Borg are an alien group dependent on technology, made up of organic and artificial life, who share a collective conscious of assimilated species' knowledge and technology, and whose ultimate goal is to achieve perfection. Most of the Borg portrayed in Star Trek are male characters who visually blend into a uniform appearance of pale bodies with technological prosthetics who act as Drones to the Borg collective. Seven of Nine was assimilated by the Borg at a young age but was liberated by Starfleet in her late twenties. The Borg Queen is a unique character among the Borg, whose intended purpose is to bring order to the chaos of the collective consciousness, and often speaks from her own right outside of the collective mind. These two female characters, and the unique differences they have in relation to their connection to the Borg collective, are what Consalvo focuses on in her analysis of gender and post-human bodies.

In her analysis, Consalvo states upfront that she thinks there are plenty of academic and popular books out there expressing the growing anxiety about modern developments in biotechnology and how they will be used. The Borg expresses that anxiety as antagonists in the Star Trek series, and allows the reader and audience to question being-ness and gender in a unique way. The female characters, Seven of Nine and the Borg Queen are interesting cases because of the distinct differences in the roles they portray. Seven of Nine is liberated from the Borg and regains some of her human-ness, and the Borg Queen acts like a queen bee to the Borg hive. On one hand, these characters can be seen as empowering. Consalvo thinks Seven of Nine is really hard to map over traditional readings of character analysis. She wonders if "her intelligence and rationality [are] a step forward for traditional female representations, or does her ambivalence about femininity bespeak a valorization of masculine norms of behavior?" (177). Consalvo wants to know what the media representations of Seven of Nine, the Borg Queen, and the Borg in general reveal about ourselves as we potentially grow more and more post-human. 
She examines these two central female Borg characters to determine how the "utopic world" of Star Trek has progressed in representing gender, as well as the post-human body, in the twentyfourth century. Consalvo expresses curiosity as to what the literature of our potential future technologies are saying and notes that humans seem to "prey" on the future with anxiety about the coming manifestations of biotechnologies. She believes these tensions "point to a heightened attention to matters of the human and its accepted boundaries" (178). Science fiction represents the embodied fears and excitement about technology and the future, but it is important to understand how they can help us mutually constitute life and scientific inquiry as we move into the future. She cites Hayles (1999), who shows that ideas about cyborgs and cyber-systems developed in scientific conferences, but also influenced "popular accounts of what it means to be "human" in everyday life" (qtd. by Consalvo 178). Consalvo argues that the way this struggle between technology and the human/post-human is represented in science fiction - "is almost always a gendered process." (179) This makes me consider how challenging it can be to create a voice for AI without associating it with a gender. Is Apple's Siri feature feminine or masculine? Would you say Siri is a woman or a man? HAL, in the film 2001: A Space Odyssey certainly sounds like a man, and Samantha, in the film Her clearly is chosen because of a binary gender interest. It seems this tactic is used purposefully for the tension that exists is almost always gendered. And it makes me question why this routine is so hard to break.

Seven of Nine is complex and contradictory, being given some typically feminine traits; she is portrayed as an athletic blonde in a skin tight jumpsuit, but avoids other traits like romantic interests (which did not show up until the end of the Voyager series, perhaps as a move to direct viewer interests). In contrast, the Borg Queen is a techno bodied femme fatale. Intended as a genderless cyborg species, Consalvo brings into question how representations of the Borg 
challenge or reinforce traditional ides about gender and the post-human body, and what that means in relation to how contemporary culture should think about it. Hayles says that technology integrated with the body leads us to questioning what it means to be human as the boundaries of what it means to be human "'are constructed rather than given"” (qtd. by Consalvo 181). But Consalvo thinks that the portrayals of Seven of Nine and the Borg Queen could point to a potential future for humanity and she wonders what effects we would prefer from technology if we were already post-human. She believes Seven of Nine and the Borg Queen can offer two examples with very different consequences.

The Borg Queen is like an overly sexualized temptress that does not seem to require the usual eye, hand, and arm prostheses that other Borg drones are assimilated with. In Consalvo's view, the Borg Queen is a throwback to the original series' depiction of women as "limited to using their bodies to achieve their goals" (184). She further believes the that Borg Queen's power is limited to her femininity, and when that fails her strategies collapse. But this portrayal seems to do a worse job than the original series in depicting the role of women because the Borg Queen fails to symbolically liberate women in the types of ways that the women in the original series had the freedom of being.

Seven of Nine and her complexity, on the other hand, has earned respect as an integral part of the ship's crew for her advanced knowledge of technology while being portrayed as a stereotypical tomboy who is also the most sexualized member of the crew. Consalvo believes that Seven of Nine's urge to re-engineer her post-human body also entails "the taking on of (a) gender" (185). And even with the excess of her femininity, her personality lacks traditional feminine markers. Seven of Nine's complexity around her central mission to "overcome her Borg assimilation" is unique because at the same time "she resists becoming fully human" (184). 
Consalvo's analysis cites Butler, who believes, "'we call ourselves into being every day"” and that we are never fully formed but "'constantly reinvent ourselves, each day becoming more complete of what we are supposed to be" (qtd. by Consalvo 185). But Seven of Nine has escaped being controlled by the collective of the Borg, and now she struggles to redefine humanity and resists gendering her body and herself. Consalvo thinks that Seven of Nine's struggle demonstrates that the "post-human takes many forms," but "to deny the importance of gender leads to a disappearance or devaluation of the feminine" (185). Although Seven of Nine is unwilling to gender her behaviors in a feminine way, in the show her appearance works against her claim to an ungendered experience. While the Borg demonstrates that traditional ideas about gender are hard to shake even for a "genderless" species, they also reaffirm the importance of looking at larger systems to determine the influence of gender and the body. Re-Imagining "Utopia"

Utopia is a central concept in what the ideal future aboard something like the Enterprise, or in any ideal place and community in science fiction. In "Popular imagination and identity politics: Reading the future in Star Trek: The Next Generation,”, Brian Ott and Eric Aoki identify the nature and function of utopian appeals towards collective imagination. They believe that future fiction constructs a cognitive framework through which its audience is taught what to imagine, instead of "how" to imagine. They explain how, in any moment of thinking, we accumulate information from the past and anticipate a future (the past is understood as memory, and the projection of the future state is understood as imagination.) Like conjuring our memories, imagination evokes mental imagery, a conceptual method the authors believe free the thinker from the types of stigma that pure prophetic and predictive speculations of the future hold, so that rather than forcing the present into the future, the projection of imagination considers how 
the future shapes the present. Memory seems more real than the imagination, but both "conjure upon mental images that are selective, biased, mutable and acutely ideological” (394).

The authors believe that the limit of a public memory could not account for the ways in which cultural texts reinforce the collective visions that inform our identities and guide our actions. They think the appeal of utopian texts is the presence of familiar and comfortable elements, and they perform a prescriptive function claiming to "depict an 'ideal' society, utopias not only suggest what is wrong with society, but they also suggest how it 'should' be different" (395). Offering readers an ideal alternative world leads readers to a focus on certain technological advancements and social relationships, and not others. They arrange our consciousness for the acceptance of certain possibilities and impossibilities.

Ott and Aoki explain that during the time Star Trek: The Next Genereation was in production, producers claimed that the show would address modern social issues, wanting to offer television that also worked in providing a message and believed that ST: TNG held to Roddenberry's vision of a utopia. The authors claim that $T N G^{\prime}$ s appeal is supported by our longing for a community responsive to and supportive of all its members -- the Enterprise is meant to symbolize this. Placing the action of $T N G$ aboard the Starfleet's Enterprise ship creates the spatial utopia in which the imagination can be explored "free from the fixed and mapped spaces of society" (397). But the authors think that TNG further naturalizes its future through appeals to the past and constrains our ability to imagine and realize potential alternatives.

Ott and Aoki's paper examines the gendering of character roles and the construction of the male gaze. They claim that unlike Kirk, Captain Picard is not stereotypically masculine, that $T N G$ both "opens gender representations" and "continues to define them relative to one another" (Ott \& Aoki 404). They believe $T N G$ further deconstructs gender stereotypes through the 
characters Troi, who serves as the Enterprise's psychological counselor, and Crusher, as the chief medical doctor. While it is empowering to give these women characters high ranking positions on the ship, I recognize that the female characters were still given traditionally feminine service roles in the series as virtually the empath and the nurse. I like Captain Picard, I'll admit, but the things I like about him are his vulnerabilities and his stoicism. I could have enjoyed a "Captain Crusher" as the stoic female captain of the bridge and Picard as a bold medical expert. But the fixed images of males holding the roles of captain, first officer, chief of security, and chief engineer, and the female roles of counselor and doctor offers the imagery that "men act and that the women take care of the men acting" (Ott \& Aoki 404). In this scope, the authors believe that masculinity is constructed as autonomous, authoritative, and active, while femininity is contrived as supportive, responsive, and passive. Conceptualizing masculinity and femininity as a "mutually exclusive duality" implies a social hierarchy in which "masculinity" is regarded as the ideal set of human norms and behaviors (Humm 163). The projection of duality into the $T N G$ 's future utopia allows viewers to "internalize an unspoken hierarchy of gender roles and relations as ideal" (Ott \& Aoki 404). This is supportive evidence of Star Trek being reiterative of traditional gender roles.

There are instances when this hierarchy is flipped; the authors make note of an episode titled, "The Best of Both Worlds," in which the Enterprise battle the Borg. In the episode, the authors point out that nearly every motive and action that favors the Enterprise comes from the initiative of one of the female characters -- Crusher, Troi, Guinan, or Shelby. When Picard is taken by the Borg, officer Riker is quickly "feminized" in relation to the ambitious, quick-witted, and hyper-masculine Shelby. Riker's "feminine" approach requires collaboration and proves to be more productive than Shelby's competitive approach, and so appears traditional gender roles 
are reversed, not ruptured. $T N G$ continues to construct the roles as mutually exclusive categories and when the "feminine" category is finally the more valued one we find a male character is enacting it.

In addition to $T N G$ 's gendering of character roles, $T N G$ narratively represents women at times as the object of a male-centric gaze, defining the objectification of women and visually treating women as objects of this curious gaze, who then "are simultaneously looked at and displayed," (Mulvey; qtd. by Ott \& Aoki 405) "By dressing women in scantily clad apparel that accentuates cleavage, $T N G$ reinforces their status as passive objects to be owned and controlled" (405 - 406). Inscribing the "male gaze" within a utopian appeal to a collective imagination, TNG "structurally limits the ability of the uncritical viewer to envision a set of social relations that does not value women in terms of their ability to arouse desire" (406).

There is an episode of $T N G$ that Ott and Aoki think most explicitly addresses gender equity issues. In the episode "Angel One," the Enterprise stumbles upon the matriarchal planet Angel One, where contemporary gender stereotypes are reversed; the men are portrayed as sexual objects that are too emotional to participate in government, and the women govern the state and work to support the men. When the Enterprise encounters a group rebelling against the social and political powers of Angel One, Riker uses his body to seduce Angel One's leader, Beata, and persuades her to overturn the death sentence and allows exile. The episode depicts its version of twentieth century gender inequities, but it fails to challenge the stereotypes that create those inequities. Riker's ability to seduce Beata functions to "legitimate the construction of women as sexual objects" (406). Riker's acceptance of the sanction leveled against the rebels suggests that segregating the minority as an acceptable solution to gender inequality, failing to transcend traditionally implemented hierarchies of gender. The results of Ott and Aoki's survey 
do seem to show great evidence of traditional gender roles being reinforced in the views from ST:TNG.

They conclude with reflecting that modes of imagining, reproducing, and renewing the collective imagination in $T N G$ functions ideologically to re-center white heterosexual masculinity by bringing its viewers to imagine a future that "renews dominant cultural codes as progressive and utopian" (409) Since our identities and actions in the present are connected to the ways in which we imagine the future, "these images function to constrain the creation of a set of social relations outside current hegemonic structures" (409). Therefore the authors believe,

Popular imagination must be contested and struggled over in the same ways as popular memory. Cultural and media critics must politicize futuristic fantasies and critically examine their role in the construction of popular imagination. The politicization of images that appeal to a collective sense of the future is all the more important in cases such as Star Trek: The Next Generation where those images make claims to utopianism. (409)

Utopian appeals in $T N G$ "re-affirm and re-center White heterosexual masculinity in popular culture" (410), and Ott and Aoki suggest we equip "strategies to 'see through' the ideology of media" and advocate a "pedagogical practice of counter-imagination," which equips reading strategies to evaluate how appeals to popular imagination "inform, shape, and structure configurations of power in the present" (410). Counter-imagination would act to provide historically marginalized subjects with strategies that empower their voices and identities, rather than excluding them. The goal is to interrogate the sites where popular imagination is constructed and connect them to the cultural politics of identity. The challenge is not to allow the collective visions of the future to be reduced to poorly established codes of injustice simply 
because they are familiar and comfortable, but strive to imagine a future outside the of current tropes of inequality. That may be something that is hard for anyone to imagine though.

\section{Damnit Jim,...}

The Ourcast/The J'naii

I've been looking for examples where Star Trek has attempted to present characters that abandon gender through its fictional portrayals of ontological and social nature in future societies. I was hoping it might be interesting to see what Star Trek could say from the positions of genderless/androgynous beings and I was curious about the J'naii, from the episode "The Outcast" (ST: TNG, S:5; e:17). The J'naii have evolved past a stage of two physical sexes into an androgynous species known for their diplomacy and kindness. The episode centers on the developing and curious romantic inclinations between Comm. Riker and a J'naii shuttle pilot, Soren, and their confrontation with the civic chamber of J'naii. Soren secretly identifies as female and has to live her life pretending to fit in or face the consequence of identifying as a gender. Comm. Riker and Soren develop a romance in the middle of a diplomatic rescue mission. Desire for Soren to be accepted for her identity comes to a climax when they are discovered and Soren is held accountable. At Soren's trial, Riker offers to give Soren asylum with Starfleet, but he is refused, and Soren ultimately chooses to go through the J'naii process of correcting genderprone behavior in order to be embraced within the J'naii. While genderless from the process of evolution, I found the casting of the J'naii in this episode to subtly appear female-centric and I was curious what might be expressed through this episodes performance of genderless beings by appearing to evolve with inheriting feminine features. 
Pronouns to address the J'naii are the first issue brought up within the opening of the episode. Soren's instructor, Krite, is on board the Enterprise with Soren, and when Comm. Riker refers to Krite as "he," Soren replies, "He? Commander, there are no he's or she's in a species without gender." Riker admits he has been struggling for days to construct sentences without using personal pronouns. He asks if he should use "it," but expresses that humans consider that disrespectful. Soren tells Riker that the J'naii use a pronoun that is neutral, but says that there is not a human translation for such a word. This connects to actual human history; in 1858 Charles Crozat Converse introduced the word "thon," which is a combination of the words "they" and “one." It did not take off with wide acceptance. Today some people prefer not to use he/she, him/her pronouns; many use "they/their instead. But even then, there seems to be a language problem in creating new words or an understanding for some things that are not common or widely familiar because of the challenge Foucault spoke of in his view of the episteme -- it is hard to establish clear understandings of emerging qualities. This moment in "The Outcast" highlights that problem; sometimes we have just as much a problem creating new words for things as we do with incorporating new ideas of people into the field of appearance. Because of the lack of clarity about emerging properties or features about beingness that may also be repressed by other forces of a prior existing belief. The scope of alternate possibilities of beingness are limited. Though, if we can so readily imagine genderless beings in science fiction, we should be able to creates new words that aim to define their existence within science fiction and see if they work to build new understandings of beingness. It does seem like that is what speculative fiction is working to do, but still it seems like there is a lack of ability to invent effective terminology for emerging ideas. But if it can be done, it can be a tool in further defining 
personal identity qualities that work to define the value of personhood outside of binary gender norms.

Back on the Enterprise, over lunch, Riker shares his father's recipe for split pea soup and says, "It keeps you warm on cold nights." Soren responds saying the J'naii prefer to sleep with a friend to stay warm. "Not to mate, ... for warmth." I think what the dialogue is engaging is how common it is for humans to assume that sleeping with someone implicitly means sex. The J'naii possibly treats encounters of this kind differently than humans because of the lack of sexual diversity in the J'naii biology. But it may be interesting to think about what that says in contrast with human sexuality and the way we culturally treat the notion of sleeping with someone; whether people from any sexual orientation consider sleeping together as implying a sexual relationship or not, to simply friendly people who sleep next to their friends while camping, it seems to be a reasonably natural and common thing to sleep together considering how ancestral gatherings of people who dwelled in caves probably did this all the time. Riker admits it is hard for him to grasp the idea of no gender (and I would argue that the writers of Star Trek do as well, for they couldn't even imaginarily create a word for within the $24^{\text {th }}$ century that would associate to genderless identity pronouns), and Soren admits it is just as hard for the J'naii to understand the "strange division" of the human species into male and female.

Soren asks Riker to confirm that he is a male; he agrees. And what I find interesting about that is it appears that Soren at least has an ability to understand that Riker appears as male, but the show doesn't explain how that assumption was made. In fact, Soren's next question is "What is it [that] makes males different from females?" Riker replies with the rhyme, "Snips and snails and puppy dog tails," and of course as we know girls are made of sugar and spice, and everything nice, and Riker says it is an old fashioned way of looking at the sexes. Soren replies 
by saying that it makes it sound better to be female. The writers choice of that rhyme is suggestive: snips and snails and puppy dog tails are figuratively parts of things, with snips being more of an expression of short temper, whereas girls have ingredients that express a dynamic range of emotional flavor, which are primarily behavioral traits. The rhyme operates to separate feminine qualities from the masculine, which is a matter of gender performance, and not sexual identity. Clarity about sex and gender becomes unclear and muddled here.

Riker goes on to claim that there are real differences between male and females; "that men are physically bigger and stronger in the upper body, that males and females have different sexual organs, and that men cannot bear children." Distinguishing between sex and gender becomes blurred. Defining traits of feminine and masculine performances helps, but in this scene in "The Outcast," it seems the terminology for asking questions about sex, male and female, overlaps with the terminology of asking questions about gender, men and women. Soren asks if males and females have different emotional capacities, and Riker responds in a way that eludes knowing by saying, "it would take a lifetime to answer." The episode skips an opportunity to talk about emotional spectrums within the different sexes, and this may be self-evident by Riker's comment, but I am still curious what that possibly says about what we assume are the true differences between men and women, when possibly we assume too much.

Riker asks what life is like on a planet with no gender, and Soren doesn't know how to reply, but Riker speculates that in a world without the battle of the sexes they "probably don't argue as much." This scene seems to imply that identification of someone's sex, or gender, different than their own, in some way equates to explicit confrontation and power struggles between those differences. But Soren does go on to clarify that for the J'naii, just because they don't have gender doesn't mean they don't like "a good fight." 
Soren becomes curious what kind of women that Riker is attracted to, and he replies saying someone who is intelligent, confident, and can equally hold a conversation with him, but that not all men like the same type of women. At this point in the episode I began to notice how this felt very familiar. I didn't feel like I was observing a genderless being truly discovering the ways of another species. I imagined re-watching this episode with the volume off, and realized that I would have assumed this story is about Riker falling in love with a woman, nothing unique. Soren does appear feminine to me, her smile is gentle and her frame looks female in contrast to the men around her; that could just be the images I see from my particular position though. But considering that this story didn't involve a J'naii falling for a woman, I think this episode is portraying Soren as feminine and Riker likewise masculine; it would have been more interesting if Soren's character pursued more of a non-traditional approach to gender roles.

Soren next becomes curious about sex organs and the reproduction and mating habits of a species with gender, and she asserts her intentions are educational. Riker says that's not usually a casual conversation between colleagues, but that the men inseminate the women and the women carry the baby. Soren tells Riker the J'naii mutually inseminate a fibrous husk where the fetuses incubate. It seems that, for the J'naii, delivering an offspring to term is a role of mutual responsibility, and Soren says the J'naii method is less risky and less painful. Riker contends that seems less enjoyable because he sees the intimacy between two people as a very enjoyable thing that brings closeness to humans, but Soren assures Riker that the J'naii have a long mating process that is full of variety and invention they find pleasurable. Soren questions if it would be possible for a human and a J'naii to be sexually compatible, but adds that it would never be tolerated in J'naii society because "the idea of gender is offensive" to the J'naii, since they believe they are a higher form of life. This reasoning comes from the J'naii's claim to have 
evolved beyond two sexes (why or how is not clear), but if the elimination of two sexes thereby eliminated gender, I am curious why gender was ultimately associated to the elimination of sex organs in the first place. We can observe that people and groups in society perform their preferred gender orientation regardless of the sexual organs they have, but the J'naii believe gender is "primitive" while relying on the presence of opposing sexual organs. I don't think gender relies on opposing sexual organs, and I could imagine a species like the J'naii performing gender regardless of the presence or absence of opposing sexual organs. This leads me to believe that the J'naii are not offering a picture of a society that has become more accepting of personal identity through expanded gender possibilities, but rather a society that is structured to eliminate gender.

Later, in the sick bay, when Soren asks Dr. Crusher what it is like to be female, Crusher replies, "it's just the way I am," she never had thought of it before. Soren points out that Dr. Crusher has longer hair than those who identify as men, that she wears make-up, and that the men don't have such elaborate hair or painted nails. The way Star Trek is defining men and women, through fashion, hair styles and make-up cannot be what defines gender. Yet, Star Trek seems to be saying that might be the case, or at least it seems through the Starfleet officers that these are the best ideas to teach someone, or an alien knowledge, about gender. Soren finds it confusing that men don't really do anything to make it appear that they want to attract a mate even when it's the most important thing on their minds. Crusher says that the men and women of the $24^{\text {th }}$ century are equals, in that, speaking of their gender, there is not one that is superior. Crusher explains that in the humans past, women were considered weak and inferior, but not anymore. However, Star Trek portrays more men in leading roles, and that this resembles current 
world inequalities in gender and the struggles of power between men and women (as well as minorities and gender non-conformists).

Star Trek offers the claim that gender is equal and none are superior, rather than show that it is the case with empowering women and diverse orientations of people. It simply offers a more contemporary view of a traditionally binary gendered system of men and women. It becomes apparent in the episode as Riker and Soren are essentially flirting, and Soren appears to be taking more of a submissive role to Riker's lead; he informs Soren what is most appropriate and Soren follows.

The episode shows members of the Enterprise playing a game of poker. Lt. Comm. Worf says that wild cards in poker are for a woman's game because it favors the weaker hands. I find this scene to further support that ideas of hegemonic masculinity still exist in Star Trek's more equitable society. Though, it is interesting that this thought is expressed through a Klingon and not a human being, because it takes the burden off of our direct human reasoning and places it within the realm of a member of Starfleet whose species is known for its beliefs in dominant power roles. Worf says he doesn't like the J'naii, but doesn't offer a clear reasoning as to why he thinks this, or why inter-species romance bothers him. Worf's thoughts seem to protest the elimination of gender, and I think this scene acts to reinforce traditional ideas of gender norms.

Eventually, Riker is told Soren is attracted to him. Soren explains that it is dangerous to be attracted to Riker because on J'naii it is prohibited, but that there are some who are born different, who are "throwbacks" to a time when their species had a gender, some drawn to maleness and others femaleness. Soren admits to identifying with femaleness and says it's dangerous because those who are "different" are shamed and ridiculed, and are sent to undergo "psychotectic therapy" to have all gender eliminated in order to be accepted into the J'naii 
society once again. Those who discover their gender, keep their lives secret and hidden. This type of treatment is an intolerable form of repression, and it seems that the writers are reminding us of how institutions and religious powers at times throughout history have persecuted homosexuality, sending people into treatment to "cure" them of their mental disorders and diseases. The social stigmatization that came along with this fueled hate and organized mobs and caused deaths. It was a little shocking to see this approach of "cure" therapy to be utilized in such an "advanced" species of compassion.

Soren admits to feeling feminine tendencies her whole life and shares a story about a childhood classmate who identified as being male, and she tells of the students ridiculing him, and how the boy's fear seemed to encourage those persecuting him. Soren identifies the boy as "him", and this is telling to me that those who were able to sense or realize their gender were already "seeing" and experiencing gender. Soren kept her gender discovery secret so to fit in and succeed and avoid persecution. She tells that the boy was taken away and underwent psychotectic treatment, and when he returned he had to tell the whole school how he has been cured. This left Soren terrified of speaking out in her adult life, and admits that she has had relationships with those who identified with males in her species while having to live a life of lies. Not long after, Krite discovers that Soren and Riker have been flirting as Soren offers Riker a tour of their beautiful botany on J'naii. They walk off into a garden and Riker makes a move and kisses Soren. The next day, Krite interrupts their affair and takes Soren into custody. Riker protests and interrupts the hearing of the charges against Soren. Riker wants it to be known that it was all his fault, that he was attracted to Soren and that he pursued her and insisted. He claims that he knew nothing was wrong until after he did it, at which point Soren rejected him. 
Soren is asked if this is true, to which Soren says, "No." Soren says she is tired of the lies and proclaims to Noor and the council chamber that she has been female her whole life. Soren defends that she is not unnatural or sick for feeling this way, and she does not need to be helped or cured. Soren says what she needs, and what all people like her need, is their acceptance and compassion. That they laugh, and talk, and do all the same as those who reject gender, that they are exactly alike in all other ways. This moment in the episode really speaks to the era in our own lifetime that struggles with those who do not accept people who are different or discriminate against those who do not conforms to traditionally prescribed gender norms of our society's past. Both here on Earth, and in the fictional society of J'naii, the gender non-conformists are subject to its society's cruel demand to conform, which I think may help to construct a story of the oppression that gender non-conformists face, but it doesn't help to produce a vision within which they can see an escape or a positive change.

Riker offers to give Soren asylum with Starfleet, but Soren is inevitably taken away and told that she is sick. Riker interjects with asking if maybe Soren would like to stay the way she is. But the diatribe says that the success of their treatment is effective and makes happier people. The J'naii claims that in their world everyone wants to be normal. Is it the assumed idea that everyone wants to be normal that makes some people reject others ideas of gender, or just difference in general? This may not be an original question, but perhaps a good reason to revisit and readdress these types of understanding today. Riker becomes frustrated he cannot help and attempts to rescue Soren, but Soren stops him and apologizes for him getting involved in all of this, and that it was all a mistake. Soren says, "I should have known I was sick, that my urges were wrong." And so Soren rejects gender and embraces it as illness. This does not help to speak to the gender non-conformists population of Star Trek's potential audience. It is really a sad 
acceptance of defeat. Star Trek seems to be normalizing the assimilation of the "others" into conforming to society's ways, or this society expresses the explicit erasure of gendered statuses.

Riker confesses his love for Soren, to which Soren replies, "I'm sorry." And I feel like this episode ends on a sad note of their relationships being destroyed around the repression of gender identity and the pressure to conform to societally enforced norms. Riker is heartbroken, but Soren seems content with the treatment that has cleared gender from her mind. This episode seems to offer the appeal towards normalizing to the standards of society. The representation of these beings who have evolved beyond the battle of the sexes by eliminating gender have not transcended the injustice of discriminating against "others" who are different, and does not allow them to be free to express their gender. I do not think the J'naii offer a good way of treating the matter of gender, but simply view them as barbaric and outlawed. That doesn't seem to be a good way to speak of an equitable society for people who are gender fluid, or those who want to express their gender freely and without constraint. Riker's offer to give Soren asylum among Starfleet is the right thing to do because he is trying to liberate Soren's desire to express the gender she identified with.

I think this episode would have spoken louder about accepting alternate and nontraditional gender expressions and roles if the character Soren was portrayed by a male who identifies with the feminine. And I am curious if Riker was attracted to Soren only because Soren's feminine qualities were not hidden, or at least they did not appear that way to me. I saw the J'naii as a gender neutral society that "appeared" characteristically feminine in appearance and expression. When J'naii figures of authority spoke, they remained very calm and did not have the assertive tone that, for example, Captain Picard or Captain Kirk would have when dealing with their opponents or the figures under their authority when being directive. The J'naii 
had gentle appearances that did not look outwardly masculine, and although I assume part of their appearance is a blend of two sexes merging into one sex, the product of their evolution appears to have inherited feminine qualities and not masculine ones. Nobody had facial hair in the J'naii. I believe that the chosen actors and the production of the J'naii were designed and portrayed the way they were to encourage the audience to feel comfortable with the J'naii as a species. I think it would have been received more standoffish by audiences if the J'naii were cast by all male actors trying to appear gender neutral, and the enforcement of gender neutrality among the J'naii may have appeared more threatening through patriarchal resemblance. I believe this perceived bias of how we often recognize gender in our daily lives also makes it very tough for modern film and television productions to offer a neutral gender form or appearance.

\section{Prime Directive}

There was a moment in my youth when I thought that Star Trek was showing me that there was a more peaceful world on the horizon, and along the way I began to put my trust in the stories and ideas Star Trek was offering about intergalactic diplomacy and ultimate personal freedom within our future society. But over the years I developed perspectives which considered what it is like to be part of a marginal demographic, through my personal struggles in life and the shared experiences and testimonies of discriminated-against others. I started processing stories I read and watched through a lens of asking "where do I exist in this story?" I slowly realized there were many stories that didn't account for me, or my needs, in different ways. A larger world of people and needs that are overlooked became apparent to me. At some point I routinely began looking at material asking "where is 'this"”, or, "why isn't 'that' included?", or, "why didn't 'it' take 'this' course or option?" "This", "that" and "it" are used to express whatever potential 
known things are not present, or what potential possibilities are not considered as alternatives. With Star Trek, I found myself at a point where I asked, why do all the gender roles in this show seem to hold to such a strong binary order, where the masculine traits and roles always seem to take dominance over feminine traits and roles? Is it our conception and understanding of what "feminine" is that always presupposes its submission to "masculine?" It would be expansive to the intellect, I would argue, to encounter novel fiction, for example, that has placed men as subordinate to women without having to inherit masculine familiar traits of power and order.

I have tried to find stories that just flip the script on such largely embedded ideas about the way of the world, as a test to see what is out there. I have gone to local comic book stores and spoken to the general community of graphic novel readers, as well as sought out the opinions of industry professionals, and asked where there are stories that are non-anthropomorphized, because I want to find stories that are able to step outside of the perspective taken for granted by a human because of being a human. I am seeking evidence of where someone writes about the experience of the universe from anything but a human centered experience, and the proof that no one even cares to write like that, maybe says something about how nobody wants to think about anything different than the most apparent and familiar things. I think it's because humans are too comfortable in the familiar when it comes to thinking of the world at large; the human story is ego-centric and finds itself getting comfortable within reflective ideas about the world that do not challenge long-standing and deep rooted familiarities about the nature of individual people within society - extrapolated to large representations of homogenous human-ness. But when I simply wanted to find any evidence of something other than that, no one in the profession or community of readers and writers had examples of non-anthropomorphized stories to offer me. It was like the human perspective was needed in every story told even if it is a story about 
something that is not human (like for example, smiles on suns "faces" and frowns on clouds, as if the going-on of global weather had something to do with human emotion and emotional output). I would ask, "Why isn't the rain happy and the sun is sad?" It is simply because most people tend to associate sunshine with happiness and rain with the absence of that previous happiness.

Many people perceive gender in stories in a similar way, what looks like a woman and acts like a woman, must be a woman. In reality, we have examples of people who show that is not strictly the case. Cross dressing, drag queens, and people who are gender non-conformist can be viewed as those embracing the expression of their gender as not coding with a binary specific sense of gender; transsexuals and hermaphroditic people can be thought of in a medical sense as changing from one category to another but maintaining either a new or the same identity. Where is the real future in mainstream ideas of future societies? Why do present and vocal groups of people, partially or fully emerged within the present scene (real world), seem only marginally represented or absent from the depictions of human-inclusive states and societies of the future? The result of this seems prejudice or biased based on the tendency to support one main or popular concept of gender roles as well as a possible inability to imagine something different.

Representation matters. I have spoken with women who felt empowered by Wonder Woman in 2017 when Patty Jenkins directed the feature film starring Gal Gadot, and I was moved by the amount of celebration and emotion that was expressed by the black community when Ryan Coogler directed 2018's Black Panther with a production team and cast of $90 \%$ black individuals. Coogler wants to ask questions about identity in his film, like, What does it mean to be a black person or an African person? These representations appear to empowerment minority groups to feel a part of the larger whole while also carving out for differences in 
perspective of identity. I believe, then, that the lack of representations in cultural fiction about humanity's potential future can work against those who are not included in these texts, while empowering only a particular set of representations. Writers and creators can do better in imagining how to fairly speak about representing the necessary and diverse spectrum of human appearances in humanity's more equitable future.

Start Trek as an idea, cannot be held responsible for lacking representation of potential unknown qualities of emerging states of being, but the authors, and the audiences, can partake in a much more hopeful and equitable vision of the future together if social inequalities are better addressed in media culture. For example, they might by eliminate appeals to binary thinking, and always move towards showing the future as something we will have to accept as being “different." I think that Star Trek embarked from its creation in the 1960's with empowering the view of a greater society working together alongside old enemies, and inequalities, to discover further unknowns. It quickly turned against itself as time began to move rapidly forward in the real world. Television couldn't keep up with the divide in mainstream appeals towards conservative and progressive points of view, and struggled pleasing all of its audiences while still journeying onward into conventional new ideas that played with the idea of beingness and personhood. But at times it ultimately failed to produce something that would break the most traditional understandings of binary gender roles and power struggles, leaving us to still seek where no persons have gone before, hoping to define the unknown as it begins to emerge.

Star Trek has made is efforts to stay up with the times; over the course of its different series it has continued to show empowerment in figures less represented before; Captain Janeway in Star Trek: Voyager, was the first female lead Captain in the franchise, and now the new series Star Trek: Discovery, which began airing in 2017, and perhaps in an effort to make up 
for lost time, has introduced its first gay lead couple and its first black female first officer on the timeline as taking place before the events of the original Star Trek series from the 1960's. It has been well received with positive critical acceptance in reviews for its diverse representations of identity and empowerment.

Accepting that knowledge of things change and groups of people as a whole tend to progress towards what is most free, more diverse, and more tolerant (or specifically in the case of a logically more equitable future society), we should consider that there might be a need to understand and attempt to identify categories of knowledge and particular nuances in knowledge that have not fully emerged yet. But how do we do that? Well, I believe there is work that can be done within the imagination. The use of imagination is part of why I think that fiction has such a powerful force in shaping the way people come to consider things around them and have intellectual experiences they might not have otherwise; it can aid to envision and come to pursue building the future and society. During Barack Obama's presidency, the White House's .gov website had a page up that reached out to the community of science fiction; they were interested in hearing from innovative and inventive minds of the public and science fiction community about what types of technologies and space exploration the administration (and nation) should pursue and/or invest in. I found it inspiring that our government noticed how valuable creative engineering was through the history of science fiction, and that they were curious about what types of advanced ideas might be ready for harvesting for the coming American future.

Surprisingly, that page has disappeared since Trump has taken office. Nonetheless, it is a recent snapshot example of how creative ideas about the future and real world society building do come together. 
So how can we talk about something that does not already have a widely recognizable form or words in the language system to then define them? When we talk about the future we struggle to clearly account for the emerging things, and therefore struggle speaking about them in ideas of the future. That may be understandable, but in a time in history where the voice of the voiceless matter regarding equitable representation, shouldn't we understandably be making efforts to account for the existence of things that are beginning to emerge and/or shouting out for equal recognition to the whole? Shouldn't the effort then be to seek out the voiceless? I think that if novel ideas of the future only present an account for what has existed up until now then we are going to continue only talking about the ideas of the past, which makes it harder to introduce or embrace alternate and new ideas about the future. Can we ever account for how something like gender will come to be known in a future state? Let's just say we cannot; what might that say about what we "think" we are doing when we engage with stories about alternate and potential future realities? Do we find ourselves recycling traditionally repeated concepts of people and preferred forms of identity in ways that act to potentially limit understandings about change, or constrain the field of vision from considering new and alternate forms? I have a concern with how ideas about our future society assume to know what something like gender will appear like in the future without ever really envisioning much of a change away from the historically binary construct of gender. Given how the two main sexes of our species, male and female, have traditionally been modeled as equating to two emergent genders, boy/man and girl/woman, and their association with the masculine and the feminine, it seems like a crucial part of equitable representation, as far as gender diversity is concerned, is to actively work to deconstruct overabundant representations of gender binary norms with more gender neutral representations in stories and general media. 
We cannot precisely predict what the real future will live out to be in any sense of "knowing what is", but I think we can safely talk about the types of expression and diversity that are currently marginalized in representation, as well as hypothetical and new ideas about gender and identity, within the realm of fiction storytelling from and with those who identify as an unheard voice or feels their existence is not an equitable part of the future human society envisioned at large in fiction. There, we can express ideas, feelings, and possibly begin to describe and play out alternate possibilities of future societies within contemporary popular discourse about gender.

\section{$\underline{\text { Works Cited }}$}

Brown, Helen Gurley. Sex and the Single Girl, Random House, New York, 1962.

Butler, Judith. "Why Bodies Matter." presented by Teatro Maria Matos, Lisbon, Portugal. February 6, 2015. YouTube, uploaded by Lbtavares Tavares September 30, 2016 https://www.youtube.com/watch?v=IzWWwQDUPPM

Butler, Judith. Gender Trouble, $2^{\text {nd }}$ edn, Routledge, New York, 1999.

Butler, Judith. Bodies That Matter: On the Discursive Limits of "Sex", Routledge, New York, 1993.

Wallace, Carvell. "Why 'Black Panther' Is a Defining Moment for Black America." The New York Times Magazine, New York Times, Feb., 12, 2018. Web. 2018.

Consalvo, Mia. "Borg Babes, Drones, and the Collective: Reading Gender and the Body in Star Trek." Women's Studies in Communication, vol. 27, no. 2, Summer 2004. pp. 177-203

Ferguson, Kathy E. "This Species Which Is Not One: Identity Practices in Star Trek: Deep Space Nine." Strategies: Journal of Theory, Culture \& Politics, vol. 15, no. 2, Nov. 2002, pp. 181-195.

Foucault, Michel. The Order of Things: An Archaeology of the Human Sciences, New York, Vintage Books, 1994.

Foucault, Michel. “Of Other Spaces”, Diacritics 16, pp. 22-27 1986.

Hayles, N. How We Became Posthuman: Virtual bodies in cybernetics, literature, 
and informatics, Chicago: University of Chicago Press. 1999.

Humm, M. The Dictionary of Feminist Theory, Second edition. Columbus: Ohio State University Press. 1995.

Jameson, Fredric. "Progress vs. Utopia; or, Can We Imagine the Future?" Science Fiction Studies 9, no. 27, 1982. p. 151.

Le Guin, Ursula. "Listening to the Unheard Voices." Interview with Zoe Capenter. YouTube, uploaded by The Nation, 26 Jan 2018, https://www.youtube.com/watch?v=3_vzSgkjBEI.

Le Guin, Ursula. The Left Hand of Darkness, Ace Books, 1969.

Mulvey, L. "Visual Pleasure and Narrative Cinema." Feminism and Film Theory, New York, Routledge. 1988. pp. 57-68.

Nichols, Nichelle. Beyond Uhura: Star Trek and Other Memories, New York: G. P. Putnams Sons, 1994.

Ott, Brian L; Aoki, Eric. "Popular imagination and identity politics: Reading the future in Star Trek: The Next Generation" Western Journal of Communication, Salt Lake City Vol. 65, Iss. 4, 2001. p. 392-415.

Vettel-Becker, P. "Space and the single girl: Star trek, aesthetics, and 1960s femininity. Frontiers, 35(2), 2014. pp. 143-178.

Shatner, William. "Star Trek Memories." Interview with Chris Kreski, New York, Harper Collins, 1993. 65.

Star Trek: The Next Generation, "The Outcast", original air date: March, $14^{\text {th }}$, Paramount Pictures. 1992. 